\title{
PULMONARY HYPERTENSION IN SCHISTOSOMIASIS
}

\author{
BY
}

\author{
IVAN DE L. CAVALCANTI, GILVAN TOMPSON, NEWTON DE SOUZA, AND FERNANDO \\ SIMÕES BARBOSA* \\ From the Instituto de Cardiologia, Universidade do Recife, Recife, Brasil
}

Received February 22, 1961

\begin{abstract}
Although there is a high rate of pulmonary involvement in patients with schistosomiasis (Shaw and Ghareeb, 1938; Faria, 1952; Menezes, 1957) there have been few publications containing an extensive analysis of the clinical picture and hæmodynamic alterations caused by this disease. Outstanding among the few are those by Shaw and Ghareeb (1938), Kenawy (1950), Barbato (1952), Girgis (1952), El Ramly et al. (1953), and Marchand et al. (1957). The present paper aims at presenting our contribution to this subject.
\end{abstract}

\section{SUBJECTS AND METHODS}

Thirty patients with schistosomatic pulmonary arterial hypertension were studied. Twentythree of them were women. Table I shows the age distribution. Seven patients died and were submitted to complete necropsy.

All the patients had positive examination for $S$. mansoni in the stools. None of them had severe anæmia, the average hæmoglobin being $12.5 \mathrm{~g}$. per $100 \mathrm{ml}$. Complete clinical examination as well as electrocardiographic, radiological, and laboratory investigations were performed on all patients. In 14, phonocardiograms were recorded using a Cambridge Simpli-Trol machine. The twelve conventional cardiographic leads and V3R were taken with a Siemens Cardiostat apparatus. In a number of patients pulmonary function tests were carried out which are not fully discussed in this paper. All patients were submitted to cardiac catheterization according to the usual technique with the subject supine in the basal post-absorptive state. The zero level was taken at $10 \mathrm{~cm}$. above the top of the X-ray table. Pressures were recorded by a Cambridge Multi-channel Simpliscribe apparatus with a P-23B or a P-23AA strain gauge manometer. Blood gas analyses were made according to van Slyke-Neill's method (1924) in the majority: in the remainder the Castro (1955) modification of van Slyke-Neill's method (1924) or the Brinkman hæmoreflector was used. The cardiac output was calculated by the Fick principle, the oxygen consumption being determined either directly in the Collins respirometer $(13.51$.) or by collecting the expired air in a Tissot spirometer and analysing it in a Scholander apparatus.

The symptoms and signs are graded in their intensity from + to ++++ .

\section{RESULTS}

In this series women predominated in contrast to the series reported by El Ramly (1953). This is probably due to the fact that the women in the North-eastern Zone of Brazil (where all of our patients

$$
\text { * Deceased. }
$$

This paper was presented before the 16th Brazilian Congress of Cardiology held in São Paulo in July 1959. This work was supported in part by a grant from the Conselho Nacional de Pesquisas, Brasil 
came from) wash their clothing on the banks of contaminated rivers and thus are exposed to repeated infestation by the cercariæ.

Ninety per cent of the patients were from 10 to 30 years of age: none were under 10 or over 40 years old. This is probably because there is not a sufficient length of time for the pulmonary hypertension to develop before the age of 10 , and children are less exposed to the infestation. On the other hand the natural history of the disease makes survival beyond the age of 40 very unlikely.

TABLE I

Ages of 30 Patients with Schistosomatic Pulmonary Hypertension

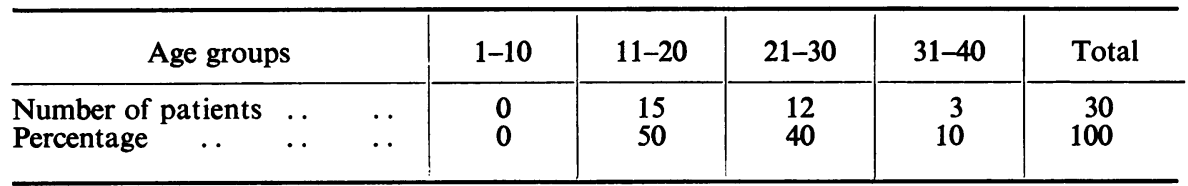

The incidence of symptoms is seen in Table II. The predominant symptom was exertional dyspnœa which occurred in 28 patients. As a rule this type of shortness of breath had a protracted evolution, from a few months to around seven years. Barbato (1952) attributes the dyspnœa to a combination of factors including ventilatory and alveolar-respiratory insufficiency, anæmia, and cardiac failure. We believe an important precipitating factor to be a limitation of cardiac output, but we have not yet sufficient proof of this.

TABLE II

Schistosomatic Pulmonary Hypertension: Symptoms

\begin{tabular}{|c|c|c|c|c|}
\hline Dyspnca & $\cdots$ & $\cdots$ & \multicolumn{2}{|c|}{28 patients } \\
\hline Palpitation & & $\ldots$ & 23 & , \\
\hline Fatigue & . & .. & 16 & , \\
\hline Effort syncope & $\cdots$ & .. & 14 & " \\
\hline Angina pectori & & .. & 5 & ", \\
\hline Hæmoptysis & .. & .. & 4 & , \\
\hline Cough ... & .. & . & 5 & , \\
\hline
\end{tabular}

Syncope during exertion occurred in 14 patients. In some of them it was incapacitating and forced them to restrict their activities considerably. They learned to avoid syncope by stopping whatever they were doing as soon as they became dizzy or their vision began to blur.

Complete loss of consciousness always occurred during effort and not afterwards, except in 2 patients. We had the opportunity of examining one within a few seconds of recovering consciousness after a syncopal attack. She was extremely dyspnœic and complained of epigastric and right flank pain. Her pulse was regular with a rate of 60 a minute and the blood pressure was 100/80 $\mathrm{mm}$. Hg. We agree with Howarth (1953) that the mechanism of the syncope is related to acute right ventricular failure.

Præcordial pain of the angina pectoris type was encountered in 5 patients. The pain was always related to effort and disappeared with rest. It may be explained, as has been suggested in other types of pulmonary hypertension, by one or the combination of various mechanisms: acute coronary insufficiency due to relative decrease of coronary flow during effort, acute distension of the pulmonary trunk, or increased right ventricular pressure in cases where it approaches or exceeds the systemic pressure thus interfering with the nourishment of the ventricular muscle. Many other patients complained of chest pain of variable character and questionable clinical significance.

Hæmoptysis occurred in 4 patients, probably due to rupture of thinned-out branches of the pulmonary arteries.

On physical examination the findings were those of pulmonary hypertension from any cause and 
TABLE III

Schistosomatic Pulmonary Hypertension: Signs

\begin{tabular}{|c|c|c|c|c|c|}
\hline Parasternal hea & & & & \multicolumn{2}{|c|}{22 cases } \\
\hline Palpable 2nd so & Ind & - & . & 26 & , \\
\hline Systolic thrill (p & llm. area) & • & & 4 & \\
\hline Systolic murmu & (pulm. area) & . & . & 22 & \\
\hline Graham Steell & urmur . . & - & & 13 & ," \\
\hline Loud pulmonar & 2nd sound & • & $\cdots$ & 30 & " \\
\hline Permanent split & of 2 nd sound & & & 21 & " \\
\hline Ejection systoli & ulmonary cli & ick & $\cdots$ & 20 & "’ \\
\hline Hepatomegaly & $\cdots$ & & $\cdots$ & & "’ \\
\hline Splenomegaly & $\cdots$ & $\cdots$ & $\cdots$ & 10 & "’ \\
\hline
\end{tabular}

they are summarized in Table III. In 28 patients the apex beat was either normal (10 cases) or non-palpable (18 cases). The systolic murmur rarely occupied the entire systole, most commonly it was protosystolic or proto- and meso-systolic. It was usually graded from + to ++ ; in 4 only it was +++ to ++++ . All patients had a loud P2 and in 19 of them the second sound was split in all phases of respiration. An ejection pulmonary systolic click was heard in 20, and on early blowing diastolic murmur was present along the second left intercostal space in 13 instances.

The arterial blood pressure was within normal limits in 29 patients; in one there was associated systemic hypertension.

Hepatomegaly was present in 25 patients, but the spleen was palpable in only 10 patients.

Electrocardiogram. Sinus rhythm was present in all the patients. In one, we recorded premature beats and in two others, a prolonged P-R interval $(0.22 \mathrm{sec}$.) but both patients were on digitalis.

The average electrical axis of $\mathrm{P}$ was $+45^{\circ}$ ranging from $+5^{\circ}$ to $+70^{\circ}$. In 2 patients, right atrial hypertrophy was present as shown by the high voltage of the $\mathrm{P}$ wave. In 8 , however, a qR or qRs pattern in V1 suggested a right atrial dilatation (Sodi-Pallares, 1956).

The average QRS axis was $+112^{\circ}$ (ranging between $\pm 180^{\circ}$ and $+60^{\circ}$ ); in 21 patients the axis was between $+100^{\circ}$ and $+130^{\circ}$ (Fig. 1). A qR or qRs pattern in V1 was found in 8 patients and $\mathrm{R}$ or Rs

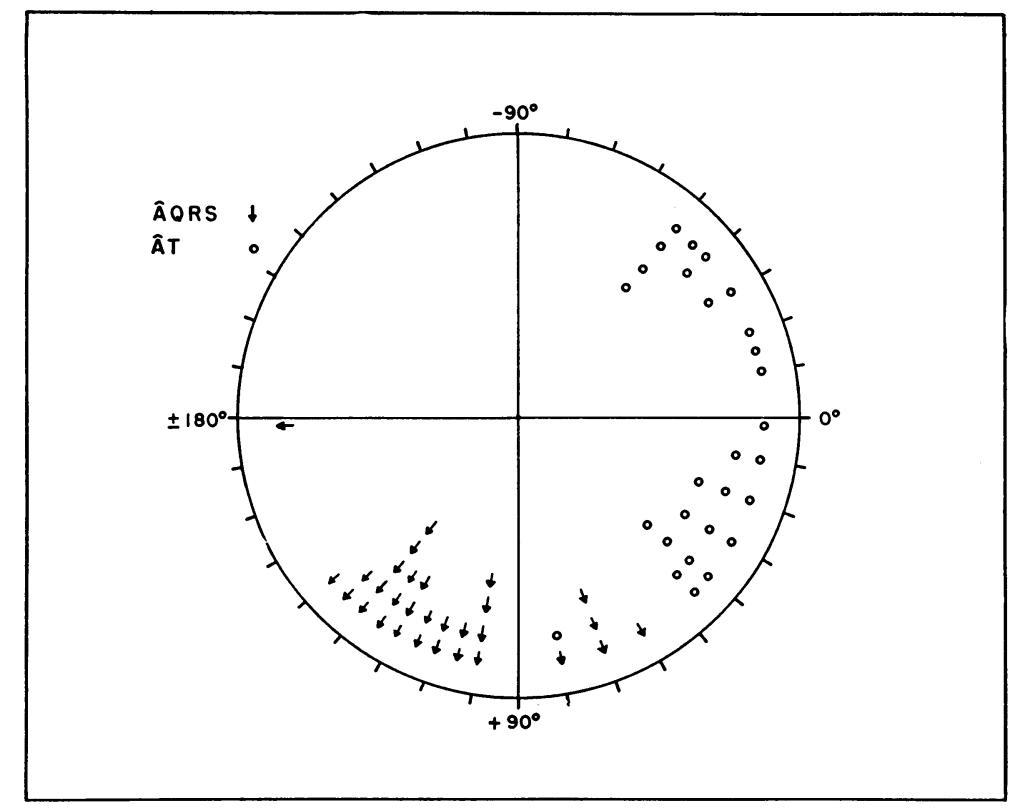

FIG. 1.-Distribution of ÂQRS and ÂT. 
in 18. In the remaining 4 the pattern in $\mathrm{V} 1$ was $\mathrm{rS}$, rsr's' ${ }^{\prime}$, and $\mathrm{rsR}^{\prime}$ ( 2 patients). Twenty-six records showed an intrinsicoid deflection of $0.03 \mathrm{sec}$. or more. In V6 the most frequent pattern was Rs (14 patients). In only 6 instances did we see a qRs pattern. With one exception, the intrinsicoid deflection in V6 was never more than 0.03 sec. A typical electrocardiogram is shown in Fig. 2.

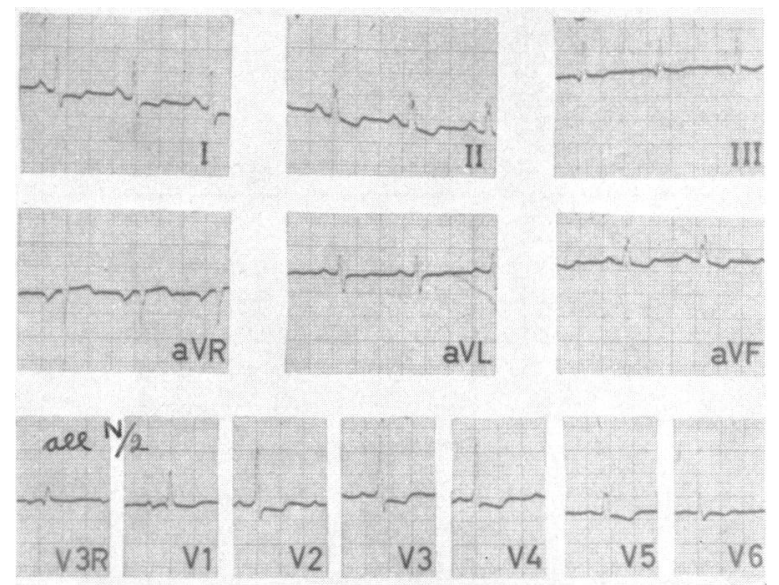

FIG. 2.-Typical electrocardiogram in schistosomatic pulmonary hypertension.

Incomplete right bundle-branch block pattern was recorded in two patients. The duration of the QRS was never above $0 \cdot 10 \mathrm{sec}$. In none of them did we see a picture of low voltage in the standard or præcordial leads.

Negative T waves in II, III, aVF, V3R, and V1 were often found. In all but one there was a depressed and convex S-T segment, usually in the leads reflecting the potential of the right ventricle. In some patients this downward displacement of the S-T segment extended up to V5 or V6. In 13 the morphology of the $T$ waves suggested the presence of primary as well as secondary changes.

The electrocardiogram of schistosomatic pulmonary hypertension is much like that of primary pulmonary hypertension except for the fact that we did not find any increasing negativity of the $\mathrm{T}$ wave from V2 to V4 as described recently in cases of primary pulmonary hypertension (Tranchesi et al., 1958).

Radiological Findings. In 24 patients the heart size was slightly or moderately increased. Much cardiomegaly was not a frequent finding in our series unless there was long standing congestive failure.

The aortic knob was normal, diminished, or absent in 27 patients. The pulmonary conus was almost always bulging (27) although never attaining aneurysm-like proportions. Increased pulsation was invariably present. The left inferior border was greatly increased in only one. In all 30 patients there was right ventricular enlargement which was moderate in 23. Left atrial enlargement did not occur but right atrial enlargement was seen in 20 patients. A typical chest X-ray is shown in Fig. 3.

Our observations on hilar pulsation in this series differ from those of previous workers (Barbato, 1952; El Ramly, 1953). As a rule the hilar shadows were large, from ++ to +++ in 26 patients. Twenty-four of them showed increased hilar pulsation. In these 24 the intensity of the hilar pulsation was + in $2,++$ in $11,+++$ in 9 and ++++ in 2 patients. Barbato (1952) believes that increased pulsation occurs only when there is associated pulmonary regurgitation. In fact all our 13 patients with pulmonary regurgitation showed a marked increase in hilar pulsations, including 


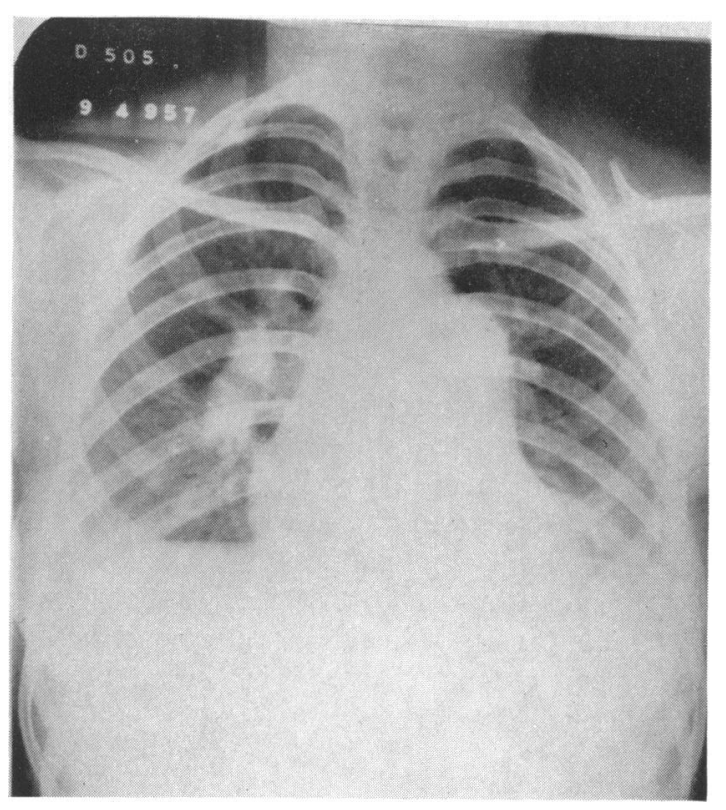

Fig. 3.-Typical chest X-ray in schistosomatic pulmonary hypertension.

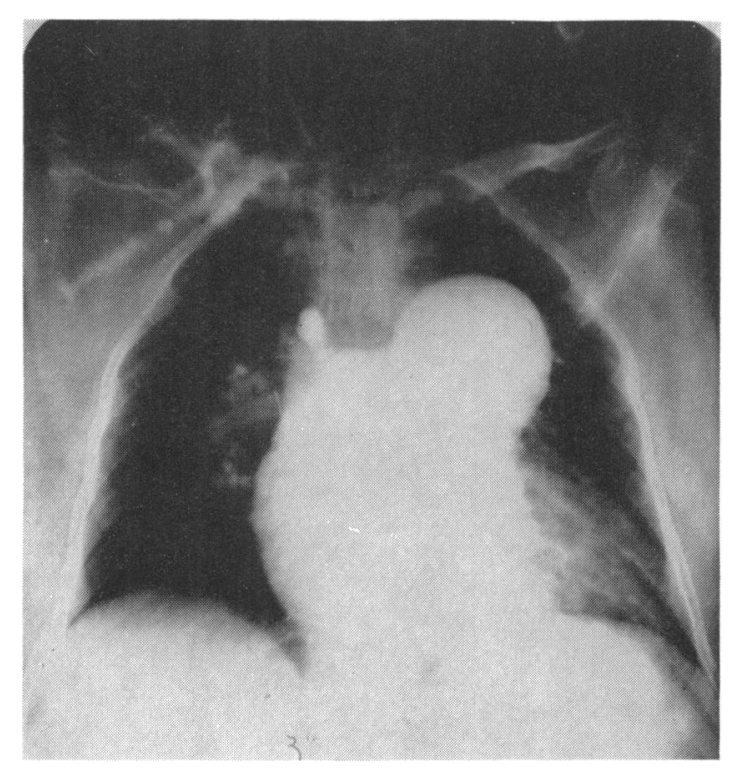

FIG. 4.-Angiocardiograms taken $3 \mathrm{sec}$. after injection. The very large pulmonary trunk is opacified. Later films showed slow passage of the contrast medium through the pulmonary vessels and narrowing of the peripheral pulmonary arteries. 
2 with grade ++++ . However, 11 patients without a diastolic pulmonary murmur also showed increased hilar pulsations. Our findings suggest that prominent hilar pulsation is always present with pulmonary regurgitation but can also occur without it.

In 12 patients the peripheral pulmonary vessels were narrowed in contrast with the increased hilar shadows. An abnormal pattern of pulmonary artery branching was found in 14 patients and sometimes multiple fine disseminated pulmonary nodules. The changes described by Erfan and Deeb (1949) were seldom seen.

The angiocardiograms confirmed the findings of the plain films. As previously described by Barbato (1952) and Vessel (1952), the contrast medium remained in the pulmonary trunk for longer than 10 seconds because of the hindrance to flow through the obstructed arterial bed, and there was an abrupt transition from secondary to tertiary and smaller arterial branches resembling the pruned branches of a tree. This corresponds to the diminution of the vascularity of the lungs beyond the enlarged hilar shadows as shown on the plain films (Fig. 4).

Hamodynamic Findings. The systolic pressure in the pulmonary artery varied between 42 and $132 \mathrm{~mm}$. $\mathrm{Hg}$ with an average of $95 \mathrm{~mm}$. In 4 patients, the pulmonary artery was not catheterized but the right ventricular systolic pressures were $102,96,98$, and $107 \mathrm{~mm}$. $\mathrm{Hg}$ respectively. These pressures together with the clinical, radiological, and electrocardiographic findings implied the presence of severe pulmonary hypertension. Table IV is a summary of the cardiac catheterization findings. Although 13 patients had pulmonary regurgitation, in only one was the pulmonary diastolic pressure lowered.

TABLE IV

Thirty Cases of Schistosomatic Pulmonary Hypertension: Physiological Data

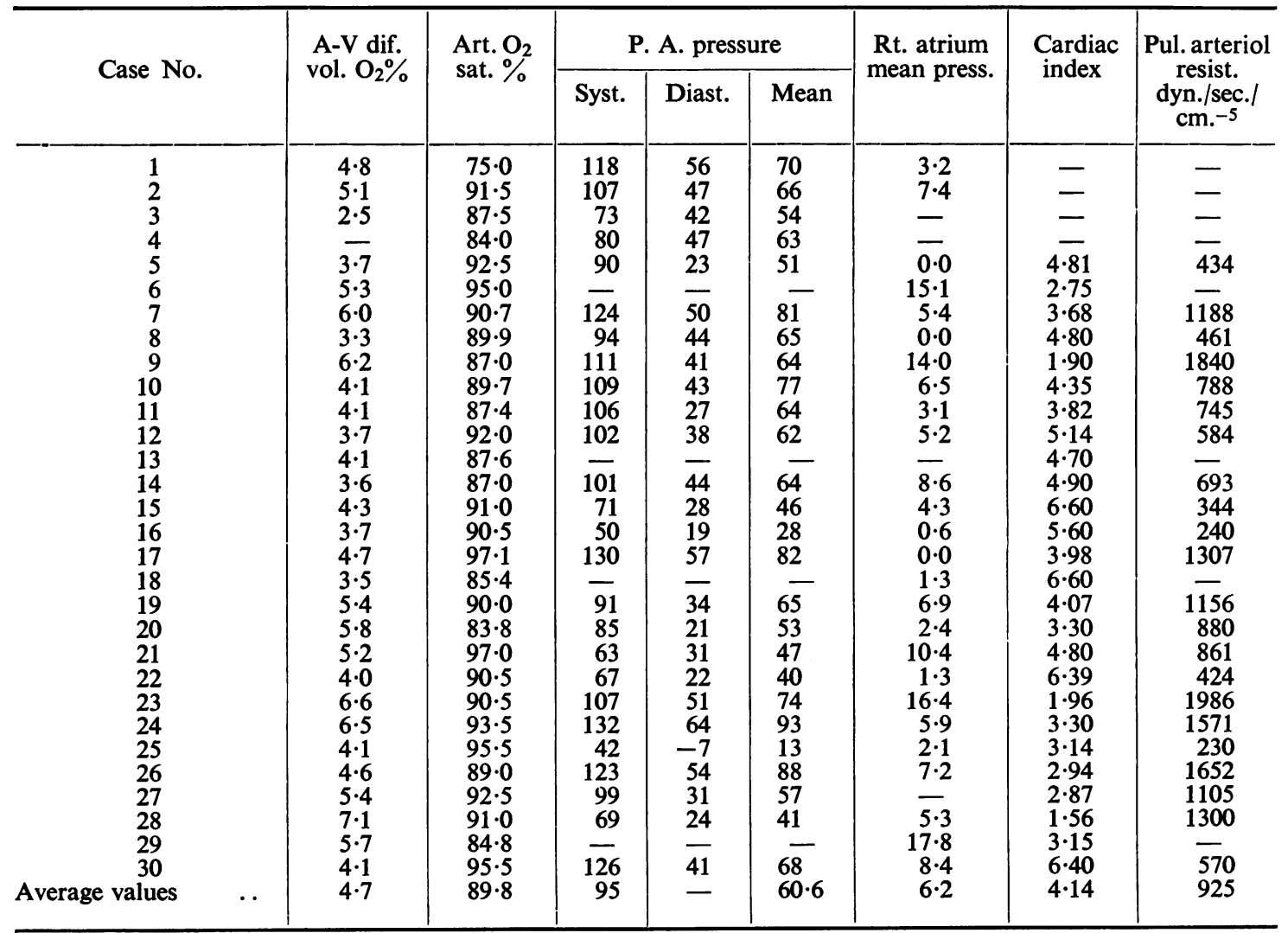


The right atrial pressures were always normal when congestive heart failure was absent. The pulmonary arterial wedge pressure was normal in the patients where it was obtained.

The pulmonary arteriolar resistance was increased in the 22 patients in whom it was estimated, with an average value of 925 dynes sec. $\mathrm{cm} .^{-5}$ (max. 1986 and min. 230) which is in keeping with the obstructive character of the pathological process.

The average cardiac output was $5.62 \mathrm{l} . / \mathrm{min}$. and the cardiac index $4 \cdot 141 . / \mathrm{m} .{ }^{2} / \mathrm{min}$. These normal resting values do not necessarily imply that they would remain normal during physical effort. We believe indeed that the inability of the heart to increase the cardiac output during effort is probably the most important single cause of the symptoms shown by these patients.

In no patient did we find evidence of a left-to-right shunt. The arterial oxygen saturation was below 92 per cent in 22 patients; the average oxygen saturation in the whole group was 89.8 per cent (range 75 to $97 \%$ ). The arterial oxygen saturation in 15 patients who breathed pure oxygen for 20 minutes either failed to reach 100 per cent or the value calculated for the dissolved oxygen was less than one volume per cent. This fact suggests that the peripheral arterial unsaturation is due to a right-to-left shunt probably through minute pulmonary arteriovenous fistulæ. This suggestion is based on the pathological findings of Shaw and Ghareeb (1938), Faria (1952), and Faria et al. (1957). However, the possibility of a veno-arterial shunt through a patent foramen ovale cannot be excluded.

Necropsy Findings. A summary of the most important pathological findings in the lungs and heart in seven cases is given in Table V. Pulmonary arterial dilatation and right ventricular hypertrophy were constant findings. Microscopically, the main extravascular lesion was the schistosomatic parenchymatous granuloma which was seen in different phases of evolution. The vascular lesions in the lungs were generally found to be widespread but areas of normal tissue were common. Lesions of the muscular arteries were the most constant. Plexiform and angiomatoid lesions were frequent, indicating, as suggested by Heath (1958), severe chronic pulmonary

TABLE V

Schistosomatic Pulmonary Hypertension: Necropsy Findings

\begin{tabular}{|c|c|c|c|c|c|c|c|c|c|c|c|c|c|}
\hline & & \multicolumn{5}{|c|}{ Case No. } & 2 & 6 & 7 & 9 & 20 & 21 & 29 \\
\hline & 象焉 & $\begin{array}{l}\text { Weight of the heart (g) } \\
\text { R.V. hypertrophy } \\
\text { Pulmonary trunk dilatation }\end{array}$ & & $\begin{array}{l}\ldots \\
\ldots \\
\ldots\end{array}$ & $\begin{array}{l}\cdots \\
\cdots \\
\cdots\end{array}$ & $\begin{array}{l}\cdots \\
\cdots \\
\cdots\end{array}$ & $\begin{array}{l}650 \\
+ \\
+\end{array}$ & $\begin{array}{l}550 \\
+ \\
+\end{array}$ & $\begin{array}{l}350 \\
+ \\
+\end{array}$ & $\begin{array}{l}350 \\
+ \\
+\end{array}$ & $\begin{array}{l}350 \\
+ \\
+\end{array}$ & $\begin{array}{l}180 \\
+ \\
+\end{array}$ & $\begin{array}{l}380 \\
+ \\
+\end{array}$ \\
\hline \multirow{4}{*}{ 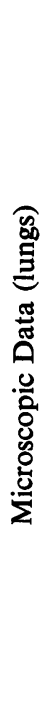 } & 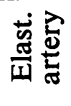 & $\begin{array}{l}\text { Proliferative arteritis } \\
\text { Intimal thickening .. } \\
\text { Plexiform lesions } \quad . .\end{array}$ & $\begin{array}{l}\cdots \\
\cdots \\
\cdots\end{array}$ & $\begin{array}{l}\cdots \\
\cdots \\
\cdots\end{array}$ & $\begin{array}{l}\cdots \\
\cdots \\
\cdots\end{array}$ & $\begin{array}{l}\cdots \\
\cdots \\
\cdots\end{array}$ & $\underline{+}$ & $\overline{+}$ & $\frac{-}{-}$ & $\underline{+}$ & $\begin{array}{l}\bar{t} \\
+\end{array}$ & $\begin{array}{l}+ \\
+ \\
-\end{array}$ & $\begin{array}{l}- \\
+ \\
+\end{array}$ \\
\hline & 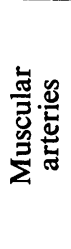 & $\begin{array}{l}\text { Intravascular granulomata } \\
\text { Thrombosis . . . } \\
\text { Necrotizing arteritis } \\
\text { Plexiform lesions .. } \\
\text { Angiomatoid lesions } \\
\text { Intimal proliferation } \\
\text { Medial thickening .. } \\
\text { Adventitial thickening }\end{array}$ & $\begin{array}{l}a \\
\cdots \\
\cdots \\
\cdots \\
\cdots \\
\cdots \\
\cdots\end{array}$ & $\begin{array}{l}\cdots \\
\cdots \\
\cdots \\
\cdots \\
\cdots \\
\cdots \\
\cdots\end{array}$ & $\begin{array}{l}\cdots \\
\cdots \\
\cdots \\
\cdots \\
\cdots \\
\cdots \\
\cdots\end{array}$ & $\begin{array}{l}\cdots \\
\cdots \\
\cdots \\
\cdots \\
\cdots \\
\cdots \\
\cdots\end{array}$ & $\begin{array}{l}+ \\
+ \\
+ \\
+ \\
+ \\
+ \\
+ \\
+\end{array}$ & $\begin{array}{l}+ \\
- \\
\dot{+} \\
+ \\
+ \\
+ \\
+ \\
+\end{array}$ & $\begin{array}{l}+ \\
+ \\
+ \\
+ \\
+ \\
+ \\
+ \\
+\end{array}$ & $\begin{array}{l}\overline{+} \\
\dot{-} \\
\overline{+} \\
+ \\
+ \\
+\end{array}$ & $\begin{array}{l}+ \\
+ \\
+ \\
+ \\
+ \\
+ \\
+\end{array}$ & $\begin{array}{l}+ \\
+ \\
+ \\
+ \\
+ \\
+ \\
+\end{array}$ & $\begin{array}{l}+ \\
+ \\
- \\
\overline{+} \\
+ \\
+ \\
+ \\
+\end{array}$ \\
\hline & $\frac{\frac{8}{0}}{\frac{0}{2}}$ & $\begin{array}{l}\text { Thrombosis ... } \\
\text { Necrotizing arteritis } \\
\text { Obliterative arteritis } \\
\text { Medial thickening } \\
\text { Intravascular granulomata }\end{array}$ & $\begin{array}{l}\cdots \\
\cdots \\
\cdots \\
\cdots\end{array}$ & $\begin{array}{l}\cdots \\
\cdots \\
\cdots \\
\cdots\end{array}$ & $\begin{array}{l}\cdots \\
\cdots \\
\cdots \\
\cdots\end{array}$ & $\begin{array}{l}\cdots \\
\cdots \\
\cdots \\
\cdots\end{array}$ & $\begin{array}{l}\overline{+} \\
\overline{-} \\
-\end{array}$ & $\begin{array}{l}\overline{-} \\
\overline{+}\end{array}$ & $\begin{array}{l}- \\
- \\
+ \\
+ \\
+\end{array}$ & $\begin{array}{l}- \\
- \\
-\end{array}$ & $\begin{array}{l}- \\
\bar{z} \\
+\end{array}$ & $\begin{array}{l}- \\
- \\
+ \\
+\end{array}$ & $\begin{array}{l}\bar{z} \\
\bar{z}\end{array}$ \\
\hline & 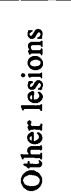 & $\begin{array}{l}\text { Schistosomatic parenchym } \\
\text { Focal pulmonary fibrosis } \\
\text { Pulmonary congestion } \\
\text { Pulmonary odema .. } \\
\text { Emphysema ... .. } \\
\text { Pleural thickening . . }\end{array}$ & $\begin{array}{l}\text { natous } \\
\ldots \\
\cdots \\
\ldots \\
\ldots \\
\cdots\end{array}$ & $\begin{array}{l}\text { granul } \\
\ldots \\
\ldots \\
\ldots \\
\ldots \\
\ldots\end{array}$ & $\begin{array}{l}\text { omata } \\
\cdots \\
\cdots \\
\cdots \\
\cdots \\
\cdots\end{array}$ & $\begin{array}{l}\ldots \\
\cdots \\
\cdots \\
\cdots \\
\cdots\end{array}$ & $\begin{array}{l}+ \\
+ \\
+ \\
- \\
-\end{array}$ & $\begin{array}{l}+ \\
+ \\
+ \\
+ \\
+ \\
+\end{array}$ & $\begin{array}{l}+ \\
+ \\
+ \\
+ \\
+ \\
-\end{array}$ & $\begin{array}{l}+ \\
+ \\
+ \\
+ \\
- \\
-\end{array}$ & $\begin{array}{l}+ \\
+ \\
+ \\
+ \\
+ \\
+\end{array}$ & $\begin{array}{l}+ \\
+ \\
+ \\
+ \\
-\end{array}$ & $\begin{array}{l} \pm \\
+ \\
\pm \\
-\end{array}$ \\
\hline
\end{tabular}


hypertension. Recently, Coelho (1960) emphasized the preferential localization of the granulomatous or proliferative lesions in small arterial branches or arterioles that arise at right angles from muscular arteries, a conspicuous finding in our cases. Two sections of lungs are seen in Fig. 5.
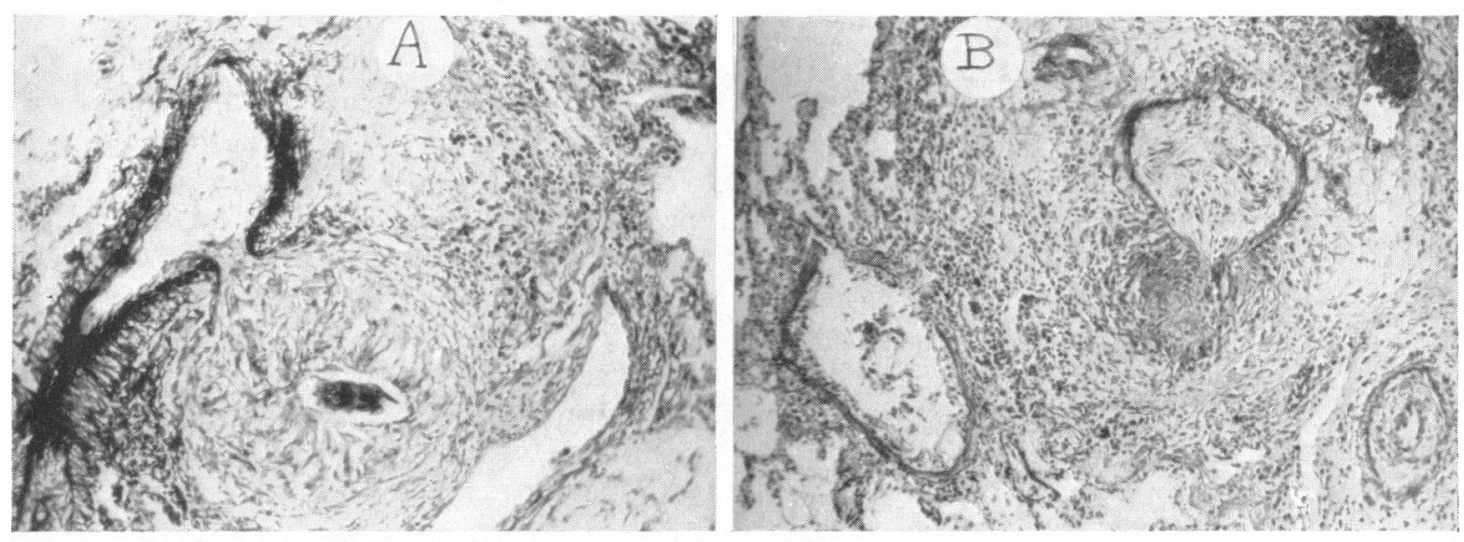

Fig. 5.-(A) Schistosomatic granulomatous reaction around an egg within a collateral branch of a muscular artery of median calibre. Verhoeff-van Gieson stain. $\times 100$.

(B) Marked proliferative process of a muscular artery and necrotizing arteritis of a thin collateral branch. Below on the right edge, intimal proliferation of a muscular arterial branch is seen. Verhoeff-van Gieson stain. $\times 80$.

\section{Discussion}

The fundamental work of Shaw and Ghareeb (1938) emphasized the role of the ova and worms in the mechanical obstruction of the pulmonary arteries leading to a focal arteritis. Later, Jaffé (1948), and more recently Faria (1952) found positive evidence that an allergic factor is important in the genesis of the pulmonary hypertension, through the production of endarteritis. Recently research with ganglionic blocking agents in this condition (Doss, 1956) strongly suggests the presence of a vasospastic factor. Lastly, the experimental work of Magalhães Filho (1959) brought to light the possibility of a fourth factor in the pathogenesis of schistosomatic pulmonary hypertension. This author observed that the passage of schistosomules through the lungs of mice, previously infected, produces a typical picture of acute arteritis with an intense allergic reaction.

Thus four factors should be considered in the pathogenesis of pulmonary hypertension in schistosomiasis, their interplay in it being variable. There are cases for instance in which the pathological picture is one of intense allergic phenomena as in several of Faria's (1952) cases. Other cases, which are less common, suggest a greater importance of the mechanical factor. The evaluation of the two other factors is more difficult to establish. As far as the vasoconstrictive factor is concerned, further intensive pharmacological studies are necessary. We have begun such studies in our laboratory using acetylcholine. The fourth factor can only be investigated by studying acute cases of the disease.

The differential diagnosis of pulmonary hypertension due to schistosomiasis can be established with reasonable certainty by using all the modern tools of diagnosis. In the first place, mitral stenosis and regurgitation and conditions causing obstruction to the pulmonary venous blood flow, must be excluded. Clinical examination, normal-sized left atrium on X-ray, normal pulmonary artery wedge pressure, and the absence of $\mathbf{P}$ wave changes in the electrocardiogram are factors that rule out these diagnoses. Septal defects and persistent ductus arteriosus are distinguished by the absence of a left-to-right shunt, measurement of the systemic and pulmonary arterial pressures at rest and during exertion, and right or left-sided angiocardiograms in obscure cases should suffice to exclude these diagnoses. The hypertensive cor pulmonale should be ruled out by the clinical findings, the X-ray appearances, and pulmonary function tests. Finally the group of diseases that lead to pulmonary hypertension by way of obstructive phenomena (such as repeated thrombo- 
embolism) and primary pulmonary hypertension must be considered. Primary pulmonary hypertension presents serious diagnostic difficulties because of the similarity of the clinical, X-ray, and hæmodynamic picture. In establishing the diagnosis of pulmonary hypertension due to schistosomiasis, the past history of the patient and the presence of ova of Schistosoma in stools or in specimens taken by rectal biopsy are fundamental. In all 7 necropsies made in this group of 30 patients, the pathological findings confirmed the presence of schistosomatic arteritis as the responsible factor leading to the pulmonary hypertension.

\section{SUMMARY}

Thirty patients with schistosomatic pulmonary arterial hypertension were studied and submitted to clinical, electrocardiographic, radiological, and hæmodynamic examination.

The predominant symptoms were dyspnœa, fatigue, palpitation, and effort syncope. On physical examination the findings were those commonly seen in pulmonary hypertension from other causes.

The main radiological features were slight to moderate enlargement of the right atrium and right ventricle, a bulging pulmonary trunk, and conspicuously enlarged and hyperpulsatile hilar shadows. The peripheral pulmonary vascular markings were diminished in one-third of the cases.

Systolic pressures in the pulmonary artery ranged from $42-132 \mathrm{~mm} . \mathrm{Hg}$ and the average pulmonary arteriolar resistance was 925 dynes $/ \mathrm{sec} . / \mathrm{cm}^{-5}$.

Arterial oxygen unsaturation was present in 22 patients; the possible explanation of this unsaturation is discussed.

The pathological findings in the lungs and heart in 7 patients are presented.

The pathogenesis of pulmonary hypertension is considered and four possibilities are presented, namely, the mechanical factor, an allergic reaction to the ova and adult worm, an allergic reaction to the schistosomules, and finally the interplay of a possible vasoconstrictive factor.

We are grateful to Prof. K. W. Donald (Edinburgh) and Prof. L. Tavares da Silva for their encouragement and advice; to Drs. E. Cabrera (Mexico) and J. C. Rocha for their advice. We are indebted to our clinical colleagues of the Instituto de Cardiologia for their collaboration and to Dr. P. Saraiva for his help in the catheterizations.

\section{ADDENDUM}

Since this paper was prepared 19 additional patients with schistosomatic pulmonary arterial hypertension have been studied, 6 of them with pathological examination of the lungs. All presented the same pattern as described in the present paper.

\section{REFERENCES}

Barbato, E. C. D. (1952). Pneumopatia e Cor Pulmonale Crônico Esquistossomóticos, Thesis. São Paulo. Castro, J. M. (1955). Arch. bras. Cardiol., 8, 347.

Coelho, R. B. (1960). An. Fac. Med. Univ. Recife. In press.

Doss, H. (1956). Pulmonary Circulation and Respiratory Function. London, E. \& S. Livingstone Ltd.

El Ramy, Z., El Sherif, A., Sorour, A., and Loutfy, A. (1953). J. Egypt. med. Ass., 36, 567.

Erfan, H., and Deeb, A. A. (1949). Brit. J. Radiol., 22, 638.

Faria, J. L. de (1952). Histopatologia da Endarterite Pulmonar Esquistossomótica, Thesis. São Paulo.

, Czapski, J., Leite, M. O. R., Pena, D. O., Fujioka, T., and Cintra, A. B. U. (1957). Amer. Heart J., 54, 196.

Girgis, B. (1952). Amer. Heart J., 43, 606.

Heath, D., and Edwards, J. E. (1958). Circulation, 18, 533.

Howarth, S., and Lowe, J. B. (1953). Brit. Heart J., 15, 47.

Jaffé, R. (1948). Arch. venez. Pat. trop., 1, 32.

Kenawy, M. R. (1950). Amer. Heart J., 39, 678.

Magalhães Filho, A. (1959). Amer. J. trop. Med. Hyg., 8, 527. Med., 100, 965.

Menezes, H. (1957). Personal communication.

Tranchesi, J., Pileggi, F., Lion, M. F. (1958). Rev. paul. Med., 53, 92.

Shaw, A. F. D., and Ghareeb, A. A. (1938). J. Path. Bact., 46, 401.

Sodi-Pallares, D., and Calder, R. M. (1956). New Bases of Electrocardiography. London, Henry Kimpton, p. 348.

Van Slyke, D. D., and Neill, J. M. (1924). J. biol. Chem., 61, 523.

Vessel, H., and Schack, J. (1952). Amer. Heart J., 44, 296. 